\title{
Correction to: Gap between patient expectation and perception during pharmacist-patient communication at community pharmacy
}

\author{
Na Eun Lee ${ }^{1}$ Myeong Gyu Kim ${ }^{1} \cdot$ Hyun Soon Sohn ${ }^{2}$
}

Published online: 16 August 2020

c) Springer Nature Switzerland AG 2020

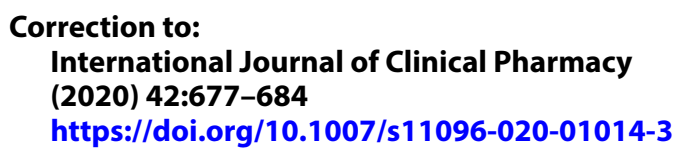

In the original publication of the article the order of authors has been interchanged and now the same has been provided correctly in this correction.

Publisher's Note Springer Nature remains neutral with regard to jurisdictional claims in published maps and institutional affiliations.

The original article can be found online at https://doi.org/10.1007/ s11096-020-01014-3.

Hyun Soon Sohn

sohn64@cha.ac.kr

1 Graduate School of Clinical Pharmacy, CHA University, 120, Haeryong-ro, Pocheon-si, Gyeonggi-do, South Korea

2 College of Pharmacy, CHA University, 120, Haeryong-ro, Pocheon-si, Gyeonggi-do, South Korea 